\title{
FACILITATING MICROMOBILITY FOR FIRST AND LAST MILE CONNECTION WITH PUBLIC TRANSIT THROUGH ENVIRONMENTAL DESIGN: A CASE STUDY OF CALIFORNIA BAY AREA RAPID TRANSIT STATIONS
}

\author{
Ferguson, Beth; \\ Sanguinetti, Angela \\ University of California, Davis
}

\begin{abstract}
Micromobility has the potential to reduce greenhouse gas emissions, traffic congestion, and air pollution, particularly when replacing private vehicle use in conjunction with public transit for firstand last-mile travel. The design of the built environment in and around public transit stations plays a key role in the integration of public transit and micromobility. This research presents a case study of rail stations in the California Bay Area, which are in the operation zone of seven shared micromobility operators. Nineteen stations and their surroundings were surveyed to inventory design features that could enable or constrain use of micromobility for first- and last-mile access. Shared mobility service characteristics, crime records, and connections to underserved communities were also documented. Key design solutions were identified based on the findings, including protected bike lanes, increased shared bike and scooter fleet size and service area, and clear signage indicating parking corral and docking points.
\end{abstract}

Keywords: Micromobility, Urban Design, Societal consequences, Social responsibility, Ecodesign

\section{Contact:}

Ferguson, Beth

University of California, Davis

Design

United States of America

bferguson@ucdavis.edu

Cite this article: Ferguson, B., Sanguinetti, A. (2021) 'Facilitating Micromobility for First and Last Mile Connection with Public Transit through Environmental Design: A Case Study of California Bay Area Rapid Transit Stations', in Proceedings of the International Conference on Engineering Design (ICED21), Gothenburg, Sweden, 16-20 August 2021. DOI:10.1017/pds.2021.419 


\section{INTRODUCTION}

Industry stakeholders, policy-makers, and academicians are imagining a more sustainable transportation system where shared micromobility and public transit supplant private car ownership as the dominant mode (Shaheen and Cohen, 2018). Shared micromobility services (e.g., on-demand, docked and dockless bikes and light electric vehicles) are rapidly proliferating, but public transit use in the US has decreased (Mallett, 2018) and faces further challenges due to the COVID-19 pandemic. Shared micromobility can facilitate public transit by providing options for first-and-last-mile connections, extending the catchment area around stations, and bridging gaps in the transit network (Shaheen and Chan, 2016). The potential for micromobility connectivity with public transit depends on a variety of factors (e.g., accessibility and safety), many of which relate to environmental design at and near transit stations.

Built environment features that promote micromobility and transit connectivity include secure networks of active travel paths as well as safe and attractive mixed-use neighborhoods with convenient access to affordable public transit (Giles-Corti et al., 2016; Zhao, 2014). For docked shared micromobility services in particular, important features include proximity of docking stations to work and home along with dense vehicle availability in multiple nearby locations to create a network (Bachand-Marleau and Lee, 2012; Shaheen et al., 2011). Protected infrastructure and lower street speed limits are associated with reduced illegal use of e-scooters on sidewalks (Portland Bureau of Transportation, 2018).

This paper presents a case study of Bay Area Rapid Transit (BART) heavy rail stations in the California Bay Area. Stations were surveyed to inventory design features in and around the stations that might facilitate or hinder the use of personal, rented, or leased bikes, e-bikes, and e-scooters for first-and-last-mile connections. Results highlight best practices, research gaps, and opportunities for improvement that can generalize to other types of transit stations and locations.

\subsection{The Bay Area and BART}

The California Bay Area was selected as the focus of this case study because it is a region with both relatively high public transit and shared micromobility use as well as high rates of using micromobility for trips to and from transit. As such, it is a potential testbed for innovative and adaptive transit station design features that support micromobility. Bay Area Rapid Transit (BART) began operation in 1972 as a heavy rail elevated and subway system designed to connect suburbs with urban centers, like San Francisco and Silicon Valley. BART has 50 stations that cover 131 miles across 5 counties and in 2019 averaged 118 million annual passengers.

\section{METHODOLGY}

A subset of 19 BART stations were selected in order to focus on those with relatively greater opportunities for use of shared micromobility. Available shared micromobility services vary throughout the region, as companies must apply for fleet use permits from each city and regulators manage permit agreements, rules, and operator exclusivity differently with each provider. Four cities with BART stations in the Bay Area currently have agreements with shared micromobility providers: Berkeley, Oakland, San Francisco, and San Jose. The 19 BART stations in these cities were the focus of this study.

Data were collected between July 2020 and April 2021 to describe the stations as well as the surrounding area within a one-mile radius, which can be considered the catchment area for first-andlast-mile travel origins and destinations. Features that past research suggests facilitate micromobility were inventoried at each station, including level of protection and connectivity of bike lanes surrounding the station; service vehicle density; micromobility parking facilities; station safety (crime rates); and features contributing to the attractiveness of the station and surrounding area (plants and outdoor seating at the stations, and nearby cafes). Data were also gathered on other relevant features, including micromobility parking affordances and signage, since signage to support way finding is a critical aspect of user experience at transit hubs (Farr et al., 2012). Data were gathered and triangulated from a variety of sources, including site visits to each of the 19 stations, Google Maps, BART and Bay Area Department of Transportation websites, city websites and shared micromobility 
service apps. Table 1 provides the codebook for data collection which includes definitions and levels of the variables assessed and data sources.

Table: 1 BART Station Survey CODEBOOK

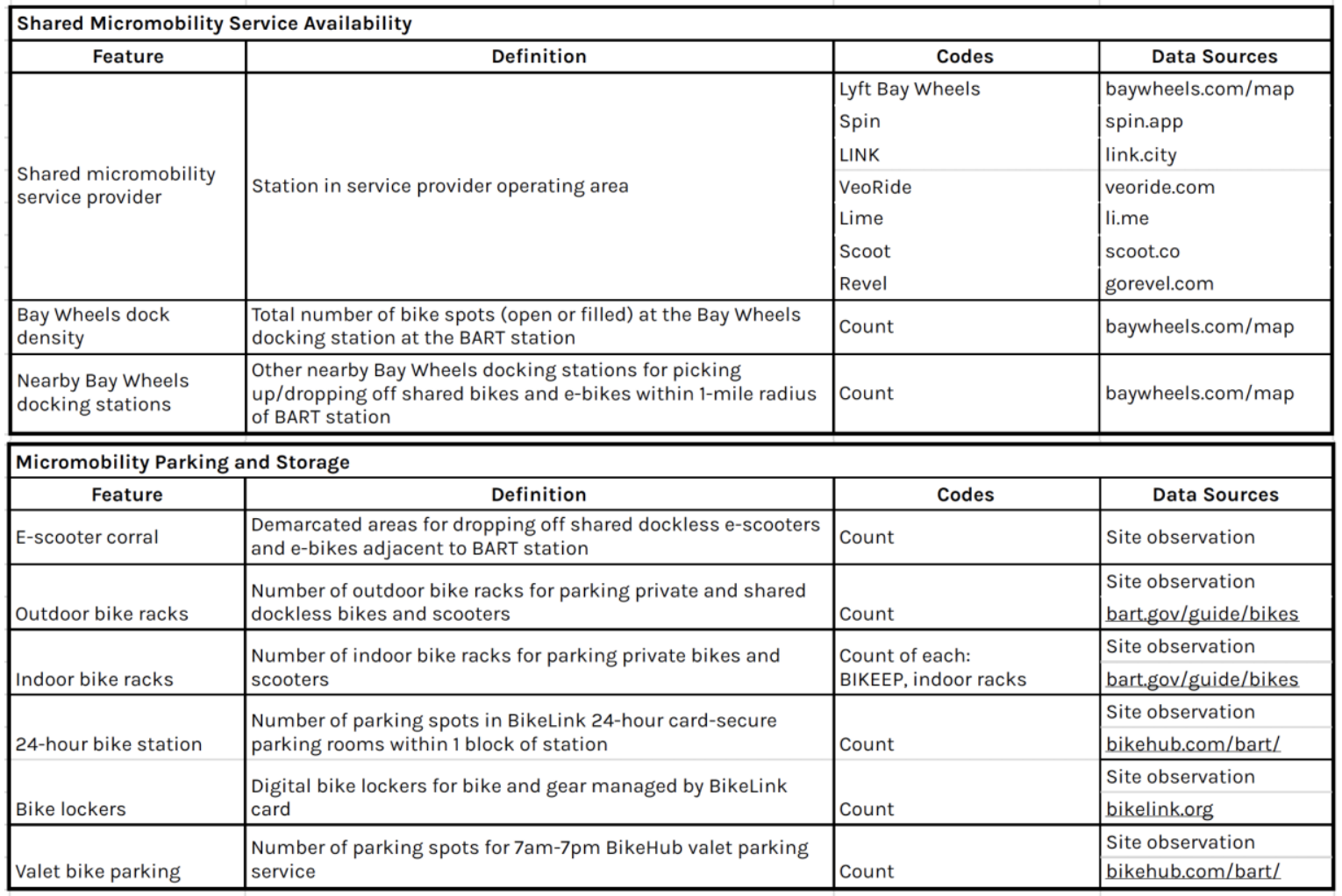

\begin{tabular}{|c|c|c|c|}
\hline \multicolumn{4}{|c|}{ Other Supportive Station Design } \\
\hline Feature & Definition & Codes & Data Sources \\
\hline \multirow[b]{2}{*}{ Signage } & \multirow[b]{2}{*}{ Content of maps and signs around station } & $\begin{array}{l}\text { Shared micromobility } \\
\text { signage }\end{array}$ & \multirow[b]{2}{*}{ Site observation } \\
\hline & & $\begin{array}{l}\text { [pictures and descriptions } \\
\text { of other content] }\end{array}$ & \\
\hline Charging facilities & $\begin{array}{l}\text { Presence of charging stations for personal e-bikes and e- } \\
\text { scooters }\end{array}$ & Yes or No & Site observation \\
\hline Bike repair facilities & $\begin{array}{l}\text { Self-service stand with tools for DIY repairs or BikeHub shop } \\
\text { with repair service staff }\end{array}$ & Self-service & bikehub.com/bart/ \\
\hline \multirow[b]{4}{*}{ Multilevel access } & \multirow{4}{*}{$\begin{array}{l}\text { Accomodations for multilevel station access for bikes and } \\
\text { scooters }\end{array}$} & Escalator & \\
\hline & & Elevator & Site observation \\
\hline & & Stairs with bike channel & \\
\hline & & Stairs without bike channel & bart.gov/guide/bikes \\
\hline Feature & Definition & Codes & Data Sources \\
\hline Outdoor seating & Presence of any seating outside the station & Yes or No & Site observation \\
\hline Cafes & Presence of cafe at station or within 1-2 blocks & Yes or No & $\begin{array}{l}\text { Site observation } \\
\text { yelp.com }\end{array}$ \\
\hline \multirow[b]{5}{*}{ Plants } & & Trees & \multirow{5}{*}{$\begin{array}{l}\text { Site observation } \\
\text { google.com/earth }\end{array}$} \\
\hline & & Shrubs & \\
\hline & & Flowers & \\
\hline & & Empty planter & \\
\hline & Presence and type of plants & Nothing & \\
\hline Crime incidents in 2019 & $\begin{array}{l}\text { Police reported crimes at BART stations during } 2019 \text { (time } \\
\text { period selected to describe stations prior to the COVID-19 } \\
\text { pandemic) }\end{array}$ & Count & bartcrimes.com \\
\hline
\end{tabular}




\begin{tabular}{|c|c|c|c|}
\hline \multicolumn{4}{|c|}{ Supportive Street Facilities } \\
\hline Feature & Definition & Codes & Data Sources \\
\hline Car lane (only) & Least supportive of micromobility & Yes or No & $\begin{array}{l}\text { Site observation } \\
\text { google.com/maps with } \\
\text { bicycling filter }\end{array}$ \\
\hline Bike boulevard (Class 3 ) & $\begin{array}{l}\text { Street lane shared by bikes, buses, and cars ( } 25 \mathrm{mph} \text { limit); } \\
\text { better than car-only but can be dangerous }\end{array}$ & Yes or No & $\begin{array}{l}\text { Site observation } \\
\text { google.com/maps with } \\
\text { bicycling filter }\end{array}$ \\
\hline Bike lane (Class 4) & Portion of road designated by striping for bike & Yes or No & $\begin{array}{l}\text { Site observation } \\
\text { google.com/maps with } \\
\text { bicycling filter }\end{array}$ \\
\hline $\begin{array}{l}\text { Protected cycle track } \\
\text { (Class 2) }\end{array}$ & Bikeway at street level with physical protection & Yes or No & $\begin{array}{l}\text { Site observation } \\
\text { google.com/maps with } \\
\text { bicycling filter }\end{array}$ \\
\hline $\begin{array}{l}\text { Greenway bike path } \\
\text { (Class 1) }\end{array}$ & Bike path with no cars & Yes or No & $\begin{array}{l}\text { Site observation } \\
\text { google.com/maps with } \\
\text { bicycling filter }\end{array}$ \\
\hline Slow street & Streets closed to through traffic for during COVID19 & Count & google.com/maps \\
\hline
\end{tabular}

\begin{tabular}{|l|l|l|l|}
\hline \multicolumn{1}{|c|}{ Other Multimodal Affordances } & \multicolumn{1}{c|}{ Codes } & \multicolumn{1}{c|}{ Data Sources } \\
\hline Feature & \multicolumn{1}{|c|}{ Definition } & Yes and No & Site observation \\
\hline TNC zone & $\begin{array}{l}\text { Presence of a designated zone (signage) for TNC } \\
\text { dropoff/pickup }\end{array}$ & Yes or No & Site observation \\
\hline Car parking & Bus stop adjacent to BART station & Count & Site observation \\
\hline Car share & Number of parking spots at BART station lots & Site observation \\
\hline Motorcycle parking & $\begin{array}{l}\text { Parking spots marked for Zip Car or Gig Car at East Bay BART } \\
\text { stations or within 3-4 blocks of SF BART stations }\end{array}$ & Count & Site observation \\
\hline
\end{tabular}

\section{RESULTS AND DISCUSSION}

Results are organized into the categories developed for the station feature design codebook and presented along with interpretations regarding implications for micromobility and transit connectivity.

\subsection{Shared micromobility service availability}

There is a high turnover rate of permitted micromobility companies, with several operators coming and going during the period over which this research was conducted. As of April 2021, seven operators have permitted fleets operating in at least 1 of the 19 stations (Table 2). Bay Wheels, a docked bike and scooter service co-managed by Lyft and two local government agencies, operates at all the stations surveyed. Bay Wheels has over 2,600 bicycles and 262 stations, including kiosks at BART stations. The other six operators have dockless vehicle services. Figure 1 maps the service boundaries of each operator along with BART stations and bike lanes.

Table 2. Shared micromobility services by city as of April 2021

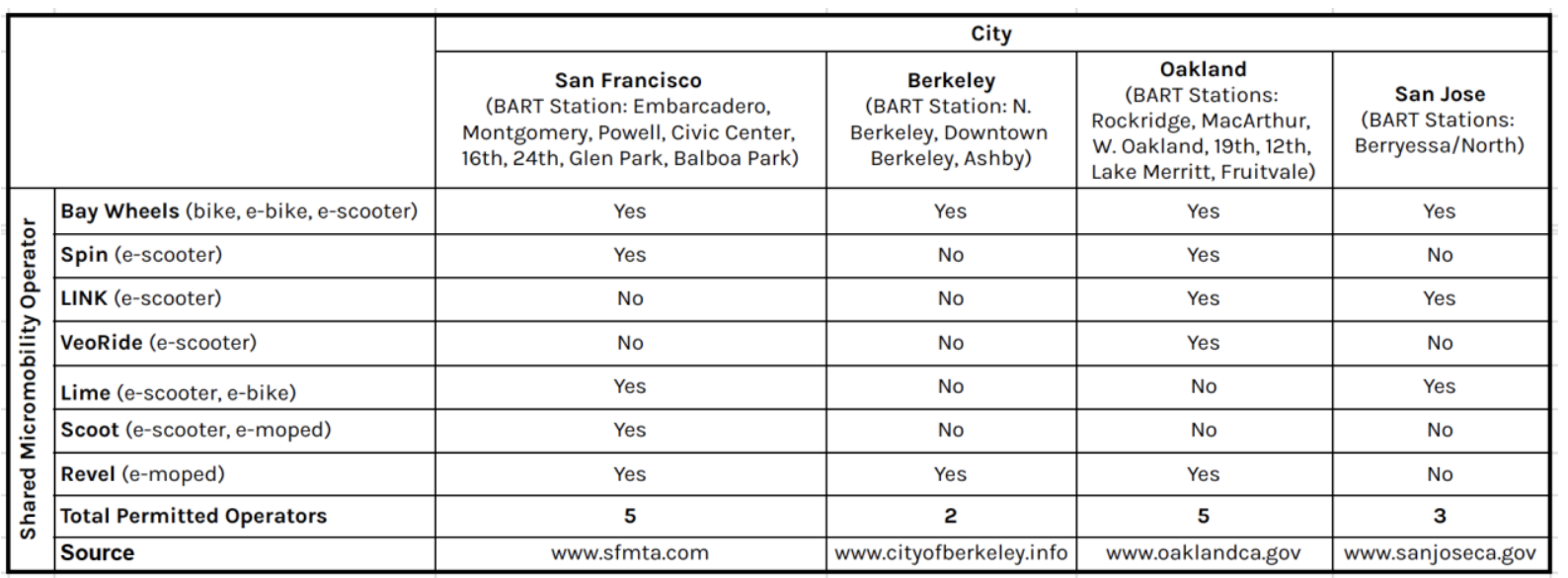




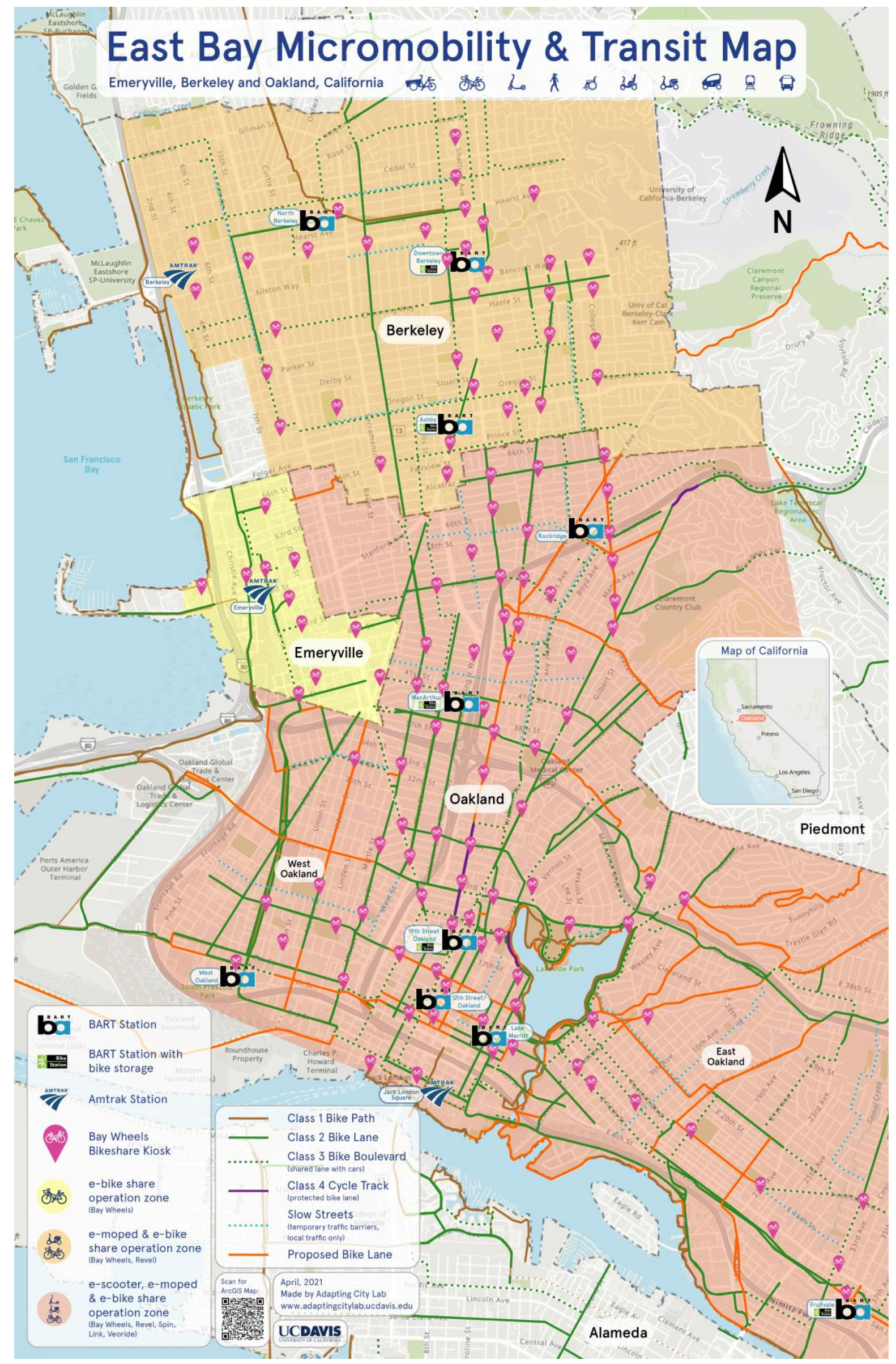

Figure 1. East Bay micromobility and transit map, B. Ferguson, J. Wattimena, 2021 
Consistency of operators across cities, as with Bay Wheels, may create a seamless experience. For example, a user could take a Bay Wheels bike from a dock near their home to a Berkeley BART station and then pick up another at an Oakland station to take to work. In contrast, the multiple dockless micromobility fleets are not consistently available across Bay Area cities. This creates complexity that could inhibit adoption because each service has its own app, vehicle types, and rules with which users must become familiar. The high turnover of operators and changing service agreements from year-to-year is also problematic; users must adapt when their preferred operators reduce or remove their fleets.

Bay Wheels kiosks at these BART stations have an average of 27 docks ( $\mathrm{SD}=6)$. The number of Bay Wheels docking stations in the surrounding neighborhood (1-mile radius) vary considerably (Mdn = 15; min-max: 2-57). As Shaheen et al. (2011) noted, a high density of vehicles at multiple locations is needed to create a network effect. BART stations with fewer nearby Bay Wheels stations are thus less conducive to last-mile access for users who live or work further from the BART station and other Bay Wheels docks.

\subsection{Micromobility parking and storage}

Parking corrals are an analogous facility to docking stations for shared dockless e-scooters and e-bikes, providing designated parking and reliable access. Corrals were present at only two stations (Figures 2-3). In the absence of corrals, shared dockless vehicle users are left without direction as to where to locate or drop off a vehicle (Figure 4). Oakland recently started requiring that all e-bikes and e-scooters be locked to a bike rack or street sign when parked (Figure 3). This prevents the vehicles from blocking a sidewalk but creates the need for more bike racks to have room for both private and shared bikes and scooters.
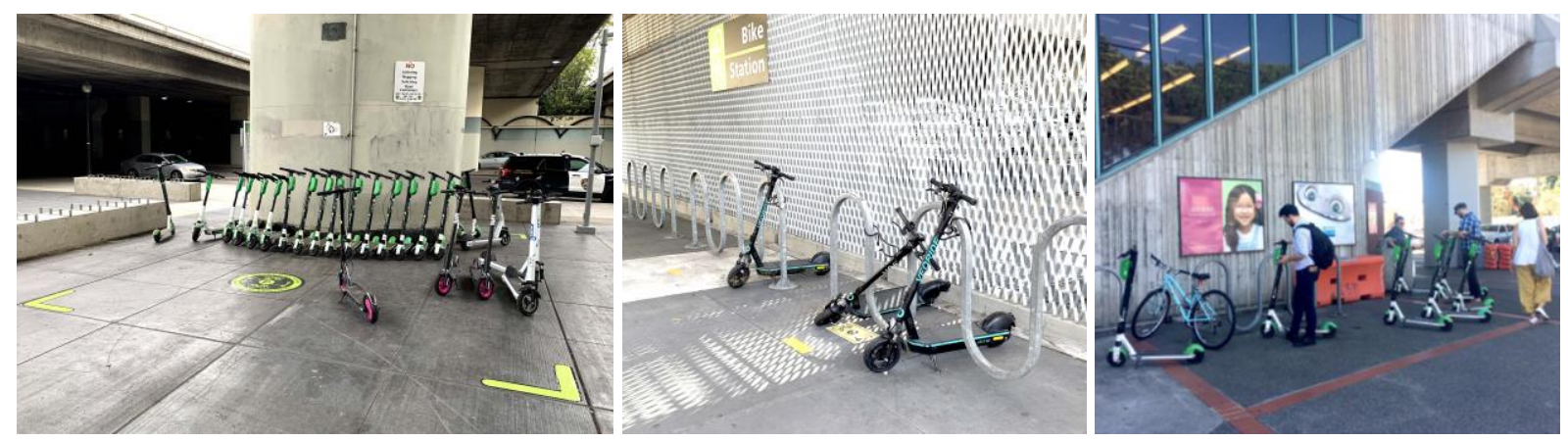

Figure 2. MacArthur BART station e-scooter coral parking

Figure 3. MacArthur BART station e-scooter lockable bike rack corral

Figure 4. W. Oakland BART station with e-scooter blocking racks in the absence of a corral

The presence and capacity of indoor and outdoor bike racks and secure private bike storage ranged widely across stations (Table 3). They were particularly limited at San Francisco stations, which are underground, and the above-ground space is limited in this high-density urban area. Outdoor racks are particularly important for facilitating shared micromobility because, unlike indoor racks and storage, they can be used to park dockless e-bikes and e-scooters (Figure 5). In the absence of outdoor racks, shared dockless e-bike users are left without direction as to where to reliably collect or drop off their vehicle (Figure 6).

Table 3. Micromobility parking and storage facilities at BART stations

\begin{tabular}{|l|l|l|l|}
\hline & East Bay \& San Jose & San Francisco & All Stations \\
\hline E-scooter corral & Present at 2 stations & Present at 0 stations & Present at 2 stations \\
\hline Outdoor racks & Mdn = 28; min-max: 2-169 & Mdn = 3; min-max: 0-12 & Mdn = 12; min-max: 0- 169 \\
\hline Indoor racks & Mdn = 14; min-max: 0-60 & Mdn = 0; min-max: 0-45 & Mdn = 0; min-max: 0-60 \\
\hline Secure storage & $\begin{array}{l}\text { Mdn = 154; min-max: } 12- \\
383\end{array}$ & Mdn = 6; min-max: 100 & Mdn = 96; min-max: 0-383 \\
\hline
\end{tabular}




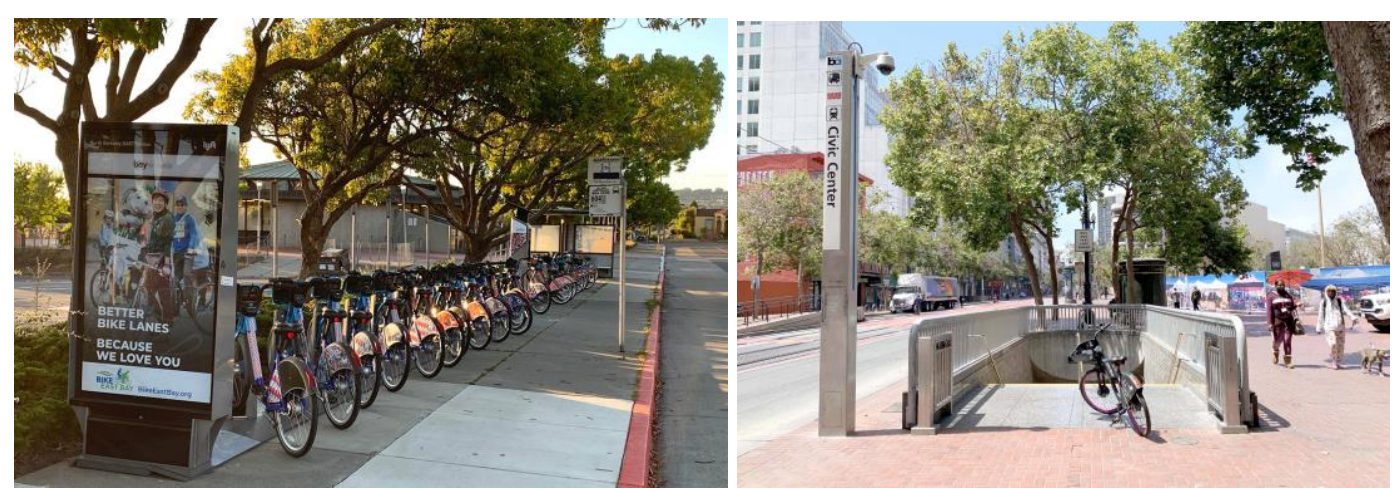

Figure 5. North Berkeley BART bay wheels bike share kiosk

Figure 6. Bay wheels e-bike parked at the top of the civic center BART station stairs

\subsection{Other micromobility-supportive station design features}

Other micromobility-supportive station features include signage, e-bike and e-scooter charging stations, bike repair services, and multilevel access and fare gate affordances for riders traveling with private bikes or scooters. Shared micromobility signage was only observed at the two stations with corrals (Figure 7), indicating where users should drop off their scooters and bikes. Signage for bus schedules and maps of stations and surrounds were prevalent, but none included place markers for Bay Wheels docking stations or corrals (e.g., Figure 8).

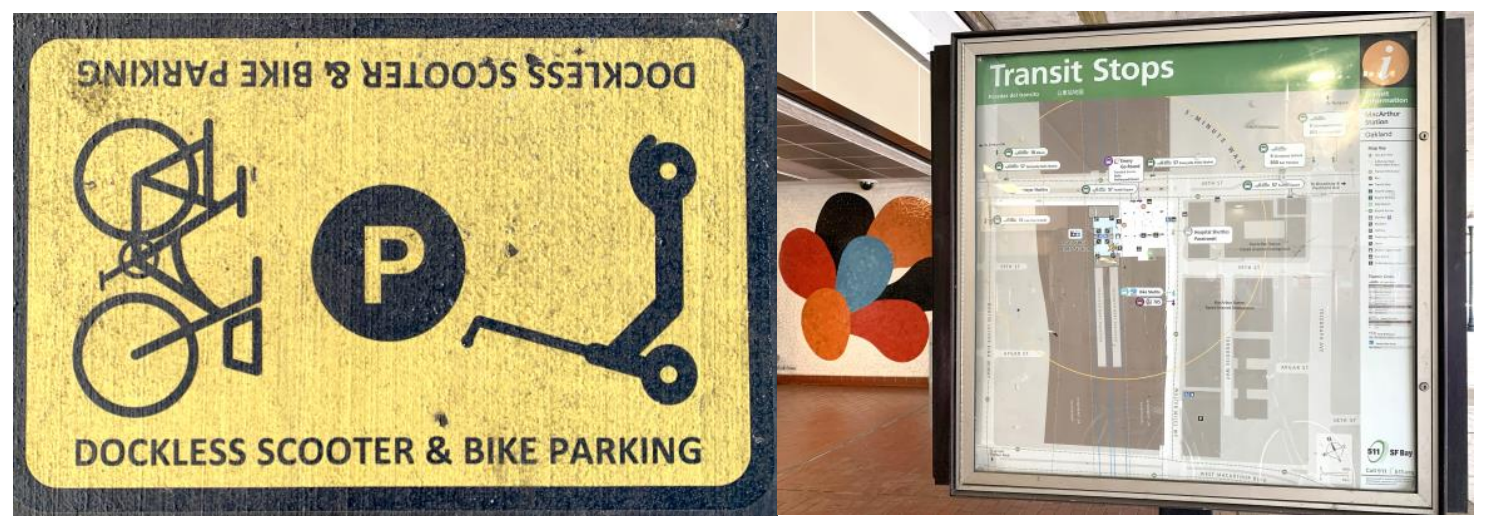

Figure 7. BART dockless scooter \& bike parking sticker marking parking corral

Figure 8. Map of transit stops around the MacArthur BART station that does not show bay wheel kiosk or the parking corral for shared dockless e-scooter and e-bikes

Only one station currently provides charging facilities for private e-bikes and e-scooters, though there are plans for charging to be included at the Downtown Berkeley station's new valet bike parking service. Several East Bay stations but none in San Francisco provide bike repair services.

BART riders traveling with a bike or stand-up scooter are instructed (via signage) to use the elevator or stairs to reach the train platforms at underground or multilevel stations. All stations have an elevator and stairs; however, these facilities are not always convenient, easy to locate, or safe. Bikes and scooters are not allowed on escalators, which are also present at every station; escalators are generally more convenient, easy to locate, and safe. Despite policy, riders were observed with bikes and scooters on escalators. BART stations have started the process of installing the first bike wheel channel alongside the stairs at the 16th Street BART station, so riders do not have to carry their vehicle up and down. All BART stations also have at least one accessible fare gate for bikes, wheelchairs, bags, and baby strollers.

\subsection{Micromobility-supportive street facilities}

Data were collected on the presence of different types of street facilities (i.e., bike lanes) that serve bikes, e-bikes, and e-scooters within a four-block radius of each BART station (i.e., the most stationadjacent part of a travelers' first-and-last-mile journeys). Figure 9 depicts the main types of bike lanes defined by the US National Association of City Transportation Officials (NACTO). Figure 1, created 
with ArcGIS and the Google Maps bike lane filter, illustrates the distribution of these different types of street facilities.

All stations had at least some nearby street segment without any type of bike lane. Most stations had nearby Class 2 classic bike lanes (84\%) and/or Class 3 bike boulevards (shared with cars; 84\%). Class 1 separated bike paths and Class 4 protected cycle tracks, which are safer and more comfortable facilities, were found near 37\% and 16\% of stations, respectively (Figure 10). There was a lack of consistency in the bike lane networks noted, including intermittent Class 2 bike lanes and Class 3 bike boulevard on the same route, bike lanes that stop altogether from block-to-block, and absence of bike lanes in streets directly adjacent to stations. Notably, there were slow streets near 58\% of stations. Slow streets have been implemented in many cities in response to the COVID-19 pandemic (including San Francisco and Oakland); a segment of street is closed to through traffic in order to support walking and biking.
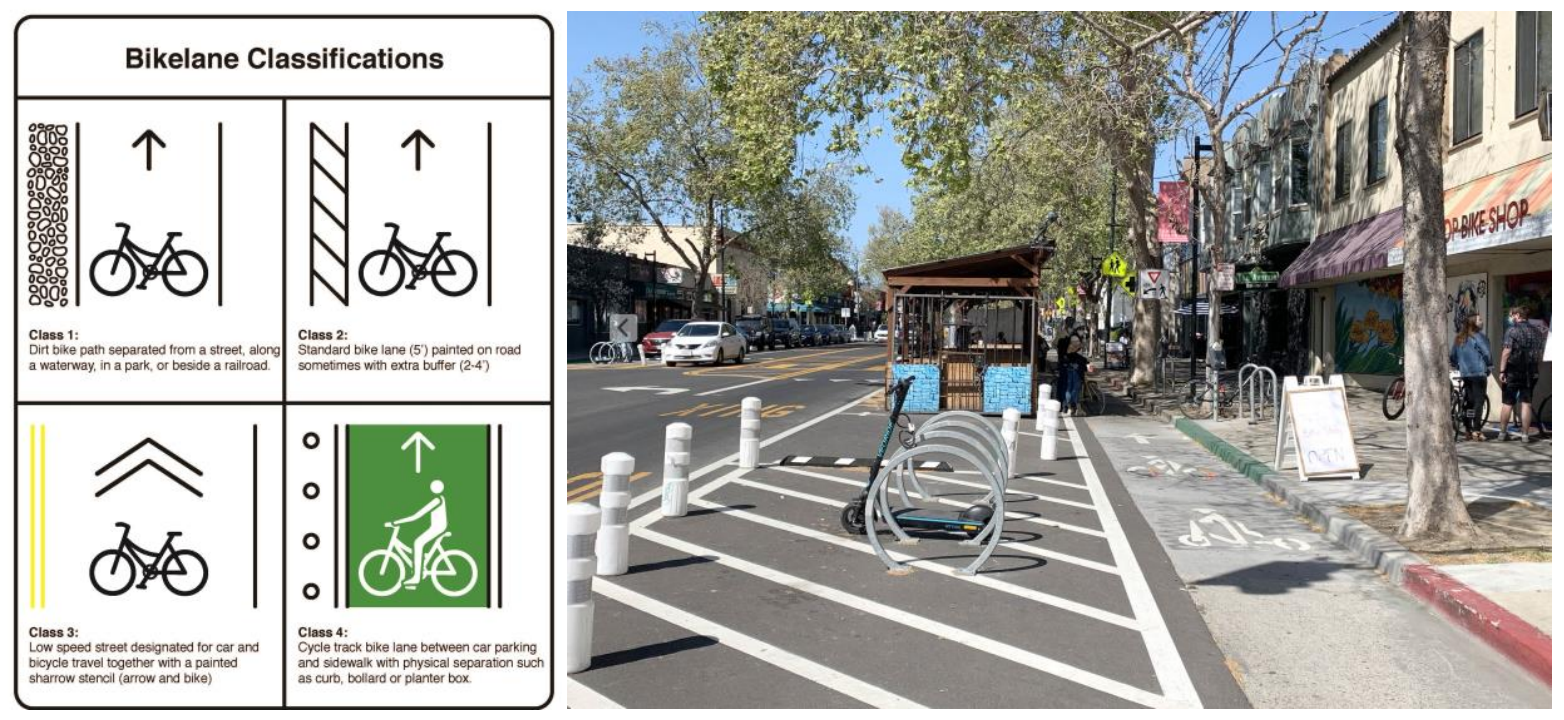

Figure 9. Bike lane classification. B. Ferguson, J. Wattimena, 2021 (data source: NACTO) Figure 10. Short segment of protected Class 4 cycle track on telegraph ave. Oakland, CA

\subsection{Station attractiveness}

Safe and attractive neighborhoods surrounding public transit stations are important to support active transportation and micromobility (Giles-Corti et al., 2016). Features that may contribute to attractiveness include outdoor seating and shade trees at stations and nearby cafes. All East Bay stations (and the new San Jose station) had outdoor seating, whereas no San Francisco BART stations did; again, this is likely due to limited above-ground space near the stations in dense urban areas. Cafes were found within 1-2 blocks of all but four stations. Greenery (specifically, trees) were observed at $63 \%$ of stations; there were empty planter boxes at two stations. Crime incidents at the stations in 2019 ranged from 7 to $108(\mathrm{Mdn}=30 ; \mathrm{n}=18)$; Berryessa BART station was excluded from this analysis since it just opened in June 2020. The high crime rate at some stations could certainly be a deterrent to use of the station and BART in general, as well as use of micromobility for first-and last-mile connections.

\subsection{Other multimodal affordances}

Designated ride-hailing loading zones have implications for micromobility safety because, in their absence, ride-hailing drivers may be interfacing with bike and scooter riders at the curbs around the station. Only $37 \%$ of the BART stations surveyed had marked ride-hailing zones, although TNCs (Transportation Network Companies) are not allowed along Market Street in San Francisco. All stations had bus connections, 47\% had car-share parking (i.e., Zipcar, GIG Car Share), $42 \%$ had car parking, and $21 \%$ had motorcycle parking. Similar to micromobility parking, car parking was much less prevalent at the denser, urban stations in San Francisco. We believe multimodal transportation options like car share and TNCs support micromobility and public transportation users to live car free while still being able to use a shared car when transporting large cargo or taking long trips. 


\section{CONCLUSION}

This research inventoried transit station design features with implications for micromobility at a subset of California Bay Area Rapid Transit (BART) heavy rail stations. This case study should reveal exemplary practices in designing for the integration of shared micromobility and public transit since it is a region where both services are heavily used relative to most other parts of the US. While many innovative features were documented, the findings also highlight areas for improvement.

Due to inconsistent availability of micromobility operators throughout the region, users may have to learn to navigate multiple service apps, use different vehicle types, and remember different rules. Stations lacked adequate parking facilities, particularly for dockless vehicles, and associated signage. Users must actively look for micromobility at transit stations or nearby streets. Stations need to prioritize corrals with racks to increase reliability and ease of use of shared micromobility services; it also helps to maintain order and protect pedestrian safety from trip hazards. Transit stations should update their printed maps and websites to highlight shared micromobility docking stations at and around the station, dockless vehicle parking zones, and recommended routes for bikes and e-scooters. Results indicated a lack of safe street facilities for bikes and scooters around transit stations. For optimal facilitation of micromobility and transit connectivity, cities and public transit agencies should work together to implement networks of protected bike lanes within a two-to-five-mile radius of transit stations. Bike lane investments and marked wayfinding around stations will improve safety and popularity for shared micromobility and cycling in general.

Many of the design principles discussed here will be beneficial to global cities managing public transit and micromobility. Micromobility stands to become an important part of public transportation, solving for the problem of first-and-last-mile connectivity and providing an alternative or complementary option for public transit users in the wake of the COVID-19 pandemic. Future research should solicit feedback from shared micromobility and transit users on their preferred station design features and attempt to quantify the influence of station design features on shared micromobility use for first-andlast-mile travel.

\section{ACKNOWLEDGMENTS}

This study was funded by the University of California Institute of Transportation Studies from the State of California through the Public Transportation Account and the Road Repair and Accountability Act of 2017 (Senate Bill 1). The authors would like to thank Sara Watterson from the University of California, Davis, Center for Regional Change and students Scott Begneski and Jovita Wattimena for their contributions.

\section{REFERENCES}

Bachand-Marleau, J., Lee, B.H. and El-Geneidy, A.M. (2012), "Better understanding of factors influencing likelihood of using shared bicycle systems and frequency of use", Transportation Research Record, Vol. 2314(1), pp. 66-71. https://doi.org/10.3141/2314-09

City of Oakland (2020), City of Oakland Announces 2021 E-Scooter Service Providers, Safety Improvements to Overall Program [online]. Available at: https://www.oaklandca.gov/news/2020/city-of-oakland-announces2021-e-scooter-service-providers-safety-improvements-to-overall-program (April 23, 2021)

Giles-Corti, B., Vernez-Moudon, A., Reis, R., Turrell, G., Dannenberg, A.L., Badland, H., Foster, S., Lowe, M., Sallis, J.F., Stevenson, M. and Owen, N. (2016), "City planning and population health: a global challenge", The Lancet, Vol. 338(10062), pp. 2912-2924. https://doi.org/10.1016/S0140-6736(16)30066-6

Mallett, W.J. (2018), Trends in Public Transportation Ridership: Implications for Federal Policy, Congressional Research Service (No. R45144). Available at: https://fas.org/sgp/crs/misc/R45144.pdf (April 23, 2021)

National Association of City Transportation Officials (NACTO) (2014), Urban Bikeway Design Guide (2nd edition), Island Press, Washington/Covelo/London.

Portland Bureau of Transportation (2018), 2018 E-Scooter Findings Report. Portland Bureau of Transportation, Portland. Available at: https://www.portland.gov/sites/default/files/2020-09/pbot_escooter_report_final.pdf (April 23, 2021)

Shaheen, S. and Chan, N. (2016), "Mobility and the sharing economy: Potential to facilitate the first-and lastmile public transit connections", Built Environment, Vol. 42(4), pp. 573-588.

https://doi.org/10.2148/benv.42.4.573 
Shaheen, S. and Cohen, A. (2018), "Is it time for a public transit renaissance?: navigating travel behavior, technology, and business model shifts in a brave new world”, Journal of Public Transportation, Vol. 21(1), p. 8. https://doi.org/10.5038/2375-0901.21.1.8

Shaheen, S.A., Zhang, H., Martin, E. and Guzman, S. (2011), "China's Hangzhou public bicycle: understanding early adoption and behavioral response to bikesharing”, Transportation Research Record, Vol. 2247(1), pp. 33-41. https://doi.org/10.3141/2247-05

Shared Micromobility. Retrieved from NACTO: https://nacto.org/sharedmicromobilityguidelines/

Zhao, P. (2014), "The impact of the built environment on bicycle commuting: Evidence from Beijing", Urban Studies, Vol. 51(5), pp.1019-1037. https://doi.org/10.1177/0042098013494423 